\title{
Knowledge and Reasons for Use of Analgesic Medications among Haramaya University College of Health and Medical Science Students, Harar Town, East Ethiopia
}

Lemlem Niguse $^{1 *}$, Teshome Sosengo ${ }^{1}$

${ }^{1}$ School of Pharmacy, College of Health and Medical Sciences, Haramaya University, Ethiopia.

*Corresponding author: Lemlem Niguse, School of Pharmacy, College of Health and Medical Sciences, Haramaya University, Ethiopia. Received date: March 07, 2021: Accepted date: April 23, 2021: Published date: April 30,2021

Citation: L Niguse, T Sosengo. (2021) Knowledge and Reasons for Use of Analgesic Medications among Haramaya University College of Health and Medical Science Students, Harar Town, East Ethiopia. Journal of Clinical Surgery and Research. 2(2); DOI: 10.31579/2768-2757/012

Copyright: (C2021 Lemlem Niguse, This is an open-access article distributed under the terms of the Creative Commons Attribution License, which permits unrestricted use, distribution, and reproduction in any medium, provided the original author and source are credited.

\section{Abstract}

Background: Analgesics, NSAIDs and opioids, commonly known as painkillers, are substances which work in various ways to relieve different types of pain experienced in the body. Approximately $25 \%$ of the patients taking non-steroidal antiinflammatory drugs face several adverse events even in case of prescribed drug and several cases of deaths are reported.

Objective: The aim of this study is to assess knowledge and reasons for use of analgesic medications at Haramaya University, College of Health and Medical Science students of Harar town, Eastern Ethiopia from March 12020 to February, 2021.

Method: Institution based cross sectional study was conduct from March 1, 2020 to February 30, 2021. Data was collected using self-administered structured questionnaire prepared in English. Stratified sampling and simple random sampling was used to select the study participants. A total sample size of 317 was taken. Then the collected data was coded, entered and analyzed by using statistical package for social science version 23 . The result is presented using tables.

Results: The $90.5 \%$ of participants had used analgesic in their life time and the $63.8 \%$ them had used analgesic in the last six months. The analgesic usage prevalence in of the study is Ibuprofen (28.7\%), Diclofenac (25.7\%) and Paracetamol (21.7\%). The $78.5 \%$ of the respondents reported that large dose of Paracetamol may cause liver. With regard to the use of alcohol with paracetamol, the $77.8 \%$ of the respondents replied that alcohols should be avoided when Paracetamol is being taken. The $60.7 \%$ of the respondents were aware of the daily maximum dose of Paracetamol. The $78.3 \%$ of respondents replied that long time use of codeine can cause addiction. In the current study the $32.4 \%, 13.2 \%$, and $12.5 \%$, of the respondents took analgesics for the reason of headache, menstrual pain and fever pain management respectively. The $38.7 \%$ of the respondents chose the analgesics due to previous experience, the $19.9 \%$ by reading a publication and the $17.5 \%$ based on recommendations from others.

Conclusion: This study showed the majority of the participants used analgesics for different reasons mainly for management of headache, menstrual pain and fever. Significant proportions of the study participants lack the appropriate knowledge about analgesics usage of analgesics.

Keywords: analgesic medications; paracetamol; ibuprofen; diclofenac

\section{Introduction}

Analgesics, NSAIDs and opioids, commonly known as painkillers, are substances which work in various ways to relieve different types of pain experienced in the body. They are also drugs which reduce or relieve the sensation of pain without producing loss of consciousness or parallel depression of other senses [1].

Non-steroidal anti-inflammatory drugs (NSAIDs) and paracetamol (acetaminophen), are the most commonly used over the-counter (OTC) drugs in the world. Over-the-counter analgesics represent a convenient solution for self-care and are generally safe if used in appropriate dosage [2]. Opioids are often the next logical step following NSAIDs in the management of acute pain and cancer-related chronic pain. They also may be an effective treatment option in the management of chronic non-cancer pain [3].

Treatment with analgesic drugs for longer period and/or with a dose exceeding maximum recommended doses has been associated with cardiovascular (CV), renal, myocardial infarction and kidney disease, both acute and chronic kidney diseases and GI complications including bleeding gastric or duodenal ulcers and GI obstructions and perforations $[4,5]$.

In a retrospective analysis of a rheumatoid arthritis patient database done in Stanford university school of medicine in California, USA, showed OTC ibuprofen and naproxen users had a relative risk for serious GI complications of approximately 3.5 compared with NSAID nonusers and 
it is estimated that $1 \%-2 \%$ of continuous NSAID users experience a clinically significant upper GI event per year [6].

Prevalence of analgesic drugs use related peptic ulcer has significantly increased and has been associated with increased morbidity and mortality $[7,8]$.

Significant proportion of NSAIDs users takes the drugs at a dosage exceeding the maximum dose, a warning or contraindication for the use of the drugs or concurrently with interacting medications [9].

In both developed and developing countries, there is a growing problem of OTC NSAIDs misuse has been reported especially among high school and university students due to the lack of knowledge regarding their proper use [10]. Studies conducted to assess students' knowledge on the use of NSAIDs have been conducted worldwide shows a lack of sufficient knowledge regarding correct use of NSAIDs among University students [11-13]. Lack of knowledge about proper use of NSAIDs lead to increased morbidity and mortality, increased risk of unwanted effects such as adverse drug reactions, unnecessary hospital admissions and visits and many other consequences.

Despite this fact, no study has been done that assess knowledge and reason about use NSAIDs Haramaya University, college of health and medical sciences students. Therefore, this study assessed knowledge and reasons for use of analgesics among CHMS students.

\section{Methodology}

\section{Study area and Period}

The study was conduct from February 1, 2020 to February, 2021 among College of Health Medical Science students in Harar town, Haramaya University, Eastern Ethiopia. Harar town is located at 525 kilometers east of the capital city, Addis Ababa. Currently a total of 1130 as regular students at Haramaya University CHMS.

\section{Study design}

Institution based cross sectional study design was conducted to assess knowledge and reasons for use of analgesic medications among Haramaya University College of Health and Medical Science.

\section{Population}

\section{Source population}

All students who were attending their education at Haramaya University College of Health and Medical Science

\section{Study population}

All selectee students who were attending their education at College of Health and Medical Science and willing to participate in the study.

\section{Sample size determination}

The required sample size is calculated by formula:

$\mathrm{n}=\frac{(\mathrm{Z} \alpha / 2)^{2} \mathrm{P}(1-\mathrm{P})}{\mathrm{d} 2} \mathrm{n}=\frac{(1.96)^{2} \times 0.5(1-0.5)}{(0.05) 2}=384$

Where:

Prevalence (p) use analgesic 50\%, $(Z)=$ standard normal distribution value at $95 \%$ confidence level of $Z=1.96$ and margin of error $(d)=5 \%$.

Since the total study population is less than 10,000 , correction formula is used to determine the sample size.

Finite population correction $(\mathrm{FPC})=\frac{n}{1+\frac{n}{N}}$

Where $n=384$

$$
\begin{aligned}
& \mathrm{N}=\text { Total population of our study }=1130 \\
& \mathrm{FPC}=\frac{384}{1+\frac{384}{1130}}=288
\end{aligned}
$$

To compensate for possible missing of information and errors, $10 \%$ of the size was add. Hence sample the final sample size $=288+28.8=317$

\section{Sampling technique}

The first sample was select using lottery methods. Using a proportionate allocation, a total sample size were divide to each regular program departments of CHMS.

- $\quad \mathrm{n}_{\mathrm{i}}=\frac{N_{i}}{N} \times n \quad$ where $\mathrm{i}=1,2, \ldots, \mathrm{k}$ where, $\mathrm{k}$ is the number of strata and

$\checkmark \quad n_{\mathrm{i}}$ is sample size of the $\mathrm{i}^{\text {th }}$ stratum

$\checkmark \quad \mathrm{Ni}$ is population size of the $\mathrm{i}^{\text {th }}$ stratum

$\checkmark \quad \mathrm{N}$ is the total number of students in CHMS

$\checkmark \mathrm{n}$ is the total sample size

Based on that, the required sample from each department;

Nurse $=89 / 1130 * 317=25$

Midwifery $=103 / 1130 * 317=29$

Clinical pharmacy $=114 / 1130 * 317=32$

Medical Laboratory Science $=84 / 1130 * 317=24$

Environmental health $=64 / 1130 * 317=18$

Psychiatry nurse $=66 / 1130 * 317=18$

Public health $=83 / 1130 * 317=25$

Medicine $=520 / 1130 * 317=146$

Finally, simple random sampling was use to select the study participants for this study.

\begin{tabular}{|c|c|c|}
\hline Department & No of students & Sample allocation \\
\hline Nurse & 89 & 25 \\
\hline Midwifery & 103 & 29 \\
\hline Clinical Pharmacy & 114 & 32 \\
\hline MLS & 84 & 24 \\
\hline Environmental health & 64 & 18 \\
\hline Psychiatry nurse & 66 & 18 \\
\hline Public health & 83 & 25 \\
\hline Medicine & 520 & 146 \\
\hline Total & 1130 & 317 \\
\hline
\end{tabular}




\section{Data collection instrument and technique}

Data was collect using self-administered structured questionnaire which is prepared in English. Participation was on voluntary basis and confidentiality was maintained.

\section{Data quality control}

To ensure data quality, the questionnaire was pretested on selected sample and subsequent correction and modification was done depending up on the finding. Finally, the collected data was reviewed and checked for completeness before the data analysis.

\section{Data processing and analysis}

The collected data was coded and analyzed by using SPSS version 24 . The result was presented by tables, graphs and charts.

\section{Ethical consideration}

Before commencing data collection ethical clearance \& approval letter was obtained from College of Health and Medical Sciences Haramaya University and was submitted to each department and then the permission letter was obtained from the respective deparments. The researcher has given full information on the purpose and objectives of the study to the study participants in order to empower the study participants to make informed decisions on whether to participate or not.

\section{Operational definition}

Analgesic: substances which work in various ways to relieve different types of pain experienced in the body.

Assessment: Evaluation and measurement of knowledge and practice about a particular matter.

Knowledge: Awareness or understanding about something overall information.

Reason: The motive or rationale for the use or application of particular subject.

\section{Results}

\section{Socio demographic characteristics}

In this study 317 respondents were included. The $169(53.30 \%)$ and 148(46.7\%) of the respondents were male and female respectively. The majority, $97.4 \%$ of the study participants were at age group of 21 to 27 years. The $288(90.9 \%)$ of them were single and the $29(9.1 \%)$ them were married.

The $146(46.1 \%), 32(10.1 \%)$ and $29(9.1 \%)$ of the participants were from medicine, pharmacy and midwifery nurse departments respectively. The majority, 141(44.5\%) and $83(26.2 \%)$ of the study participants were of fourth and fifth year students (Table 2).

\begin{tabular}{|c|c|c|c|}
\hline Variables & Socio-demographic characteristics & Frequency & $\%$ \\
\hline Age & $\begin{array}{l}\text { Male } \\
\text { Female }\end{array}$ & $\begin{array}{c}169 \\
148\end{array}$ & $\begin{array}{l}53.30 \\
46.70\end{array}$ \\
\hline Age of Respondent & $\begin{array}{l}20-22 \\
23-25 \\
26-30 \\
\end{array}$ & $\begin{array}{r}79 \\
188 \\
50\end{array}$ & $\begin{array}{l}24.8 \\
59.3 \\
15.7\end{array}$ \\
\hline Marital Status & $\begin{array}{l}\text { Single } \\
\text { Married }\end{array}$ & $\begin{array}{r}288 \\
29\end{array}$ & $\begin{array}{r}90.9 \\
9.1\end{array}$ \\
\hline Department & $\begin{array}{l}\text { Medicine } \\
\text { Clinical Pharmacy } \\
\text { Midwifery Nurse } \\
\text { Clinical Nurse } \\
\text { HO* } \\
\text { MLS* } \\
\text { Psychiatry nurse } \\
\text { Environmental }\end{array}$ & $\begin{array}{r}146 \\
32 \\
29 \\
25 \\
25 \\
24 \\
18 \\
18\end{array}$ & $\begin{array}{r}46.1 \\
10.1 \\
9.1 \\
7.9 \\
7.9 \\
7.6 \\
5.7 \\
5.7\end{array}$ \\
\hline Academic year of study & $\begin{array}{l}\text { First } \\
\text { Second } \\
\text { Third } \\
\text { Fourth } \\
\text { Fifth } \\
\text { Sixth }\end{array}$ & $\begin{array}{r}6 \\
2 \\
47 \\
141 \\
83 \\
38\end{array}$ & $\begin{array}{r}1.9 \\
0.6 \\
14.8 \\
44.5 \\
26.2 \\
12.0\end{array}$ \\
\hline
\end{tabular}

Health officer; MLS*: Medical laboratory science; CHMS*: College of health and medical sciences 


\section{Prevalence of analgesics usage}

The 288(90.8\%) had used analgesics in their life time. And 201(63.8\%) of the study participants had used an analgesic in the last six months.
From the participants who had used analgesics in the last six months, the $28.7 \%, 25.7 \%, 21.7 \%$ and $13.9 \%$ of the respondents used Ibuprofen, Diclofenac, Paracetamol and Tramadol respectively (Table 3).

\begin{tabular}{|c|c|c|c|}
\hline Variables & Analgesic usage pattern & Frequency & $\%$ \\
\hline Have you ever used analgesics & $\begin{array}{c}\text { Yes } \\
\text { No } \\
\text { I don't Remember }\end{array}$ & $\begin{array}{c}288 \\
24 \\
5\end{array}$ & $\begin{array}{c}90.8 \\
7.6 \\
1.6\end{array}$ \\
\hline Have you used analgesics in the last six month & $\begin{array}{c}\text { Yes } \\
\text { No } \\
\text { I Don't Remember }\end{array}$ & $\begin{array}{c}223 \\
88 \\
6\end{array}$ & $\begin{array}{c}70.3 \\
27.7 \\
1.9\end{array}$ \\
\hline $\begin{array}{l}\text { If "Yes" which of the following drug do you } \\
\text { used for analgesic effect? }\end{array}$ & $\begin{array}{c}\text { Paracetamol } \\
\text { Ibuprofen } \\
\text { Diclofenac } \\
\text { Aspirin } \\
\text { Tramadol } \\
\text { Codeine } \\
\text { Others* }\end{array}$ & $\begin{array}{r}50 \\
66 \\
59 \\
11 \\
32 \\
4 \\
1\end{array}$ & $\begin{array}{r}21.7 \\
28.7 \\
25.7 \\
4.8 \\
13.9 \\
1.7 \\
0.4\end{array}$ \\
\hline
\end{tabular}

Other*: Meloxicam; CHMS*: College of health and medical sciences

Table 3: Analgesics usage pattern of the study participants, CHMS*, Haramaya University, Harar, Eastern Ethiopia, Feb 2021.

\section{Knowledge towards analgesics usage}

The 277(87.3\%) of the respondents stated that Paracetamol, Ibuprofen, Diclofenac, and Aspirin can be used to relieve pain. The 164(51.7\%) respondents replied that Paracetamol, Ibuprofen, Diclofenac, and Aspirin are equally effective for relieving pain associated with inflammation. The $78.5 \%$ of the respondents reported that large dose of Paracetamol causes liver damage.

With regard to the use of alcohol with paracetamol, the $77.8 \%$ of the respondents replied that alcohols should be avoided when Paracetamol is being taken to decrease the risk of liver damage. The $60.7 \%$ of the respondents were aware of the daily maximum dose of Paracetamol.

In the present study, the $77.8 \%$ of the participants reported that alcohol should be avoided to decrease the risk of gastric irritation while taking Ibuprofen, Diclofenac, and Aspirin. The majority, 66.5\%, of the respondents in this study replied that aspirin should not be used for the treatment of pain in patients with asthma and peptic ulcer disease. With respect to the use of opioids, the $78.3 \%$ of the respondents stated long time use of codeine can cause addiction. The $64.2 \%$ of respondents replied that they read the leaflet before taking analgesic (Table 4).

\begin{tabular}{|c|c|c|c|}
\hline Variables & Analgesic usage pattern & Frequency & $\%$ \\
\hline $\begin{array}{l}\text { Medications such as Paracetamol, Ibuprofen, } \\
\text { Diclofenac, and Aspirin may be used to relieve pain }\end{array}$ & $\begin{array}{l}\text { Yes } \\
\text { No } \\
\text { I Don't Remember }\end{array}$ & $\begin{array}{c}277 \\
21 \\
19\end{array}$ & $\begin{array}{c}87.3 \\
6.6 \\
6.0\end{array}$ \\
\hline $\begin{array}{l}\text { Paracetamol, Ibuprofen, Diclofenac, and Aspirin are } \\
\text { equally effective for relieving pain associated with } \\
\text { inflammation }\end{array}$ & $\begin{array}{l}\text { Yes } \\
\text { No } \\
\text { I Don't Remember }\end{array}$ & $\begin{array}{c}164 \\
109 \\
44\end{array}$ & $\begin{array}{l}51.7 \\
34.3 \\
14.0\end{array}$ \\
\hline $\begin{array}{l}\text { A large dose of Paracetamol may cause liver } \\
\text { damage }\end{array}$ & $\begin{array}{l}\text { Yes } \\
\text { No } \\
\text { I Don't Remember }\end{array}$ & $\begin{array}{r}248 \\
29 \\
39 \\
\end{array}$ & $\begin{array}{c}78.5 \\
9.2 \\
12.3 \\
\end{array}$ \\
\hline $\begin{array}{l}\text { Large doses of Ibuprofen, Diclofenac, and Aspirin } \\
\text { may cause gastric irritation/ulcer }\end{array}$ & $\begin{array}{l}\text { Yes } \\
\text { No } \\
\text { I Don't Remember }\end{array}$ & $\begin{array}{r}257 \\
22 \\
36\end{array}$ & $\begin{array}{r}81.3 \\
7.0 \\
11.4\end{array}$ \\
\hline $\begin{array}{l}\text { When you take Paracetamol alcohol should be } \\
\text { avoided to decrease the risk of liver damage }\end{array}$ & $\begin{array}{l}\text { Yes } \\
\text { No } \\
\text { I Don't Remember }\end{array}$ & $\begin{array}{r}247 \\
24 \\
46\end{array}$ & $\begin{array}{r}77.8 \\
7.6 \\
14.6\end{array}$ \\
\hline $\begin{array}{l}\text { Do you know the maximum daily dose of } \\
\text { Paracetamol? }\end{array}$ & $\begin{array}{l}\text { Yes } \\
\text { No } \\
\text { I Don't Remember }\end{array}$ & $\begin{array}{r}193 \\
58 \\
66\end{array}$ & $\begin{array}{l}60.8 \\
18.4 \\
20.9\end{array}$ \\
\hline $\begin{array}{l}\text { When you take Ibuprofen, Diclofenac, and Aspirin } \\
\text { alcohol should be avoided to decrease the risk of } \\
\text { gastric irritation }\end{array}$ & $\begin{array}{l}\text { Yes } \\
\text { No } \\
\text { I Don't Remember }\end{array}$ & $\begin{array}{r}247 \\
34 \\
36 \\
\end{array}$ & $\begin{array}{l}77.8 \\
10.8 \\
11.4\end{array}$ \\
\hline $\begin{array}{l}\text { Aspirin should not be used for the treatment of pain } \\
\text { in patients with asthma and peptic ulcer disease }\end{array}$ & $\begin{array}{l}\text { Yes } \\
\text { No } \\
\text { I Don't Remember }\end{array}$ & $\begin{array}{r}211 \\
35 \\
71\end{array}$ & $\begin{array}{l}66.5 \\
11.1 \\
22.5\end{array}$ \\
\hline Long time use of codeine can cause addiction & $\begin{array}{l}\text { Yes } \\
\text { No }\end{array}$ & $\begin{array}{r}248 \\
24\end{array}$ & $\begin{array}{r}78.3 \\
7.6\end{array}$ \\
\hline
\end{tabular}


Table 4: Knowledge towards analgesics usage, CHMS, Haramaya University, Harar, Eastern Ethiopia, Feb 2021.

\section{Reason for analgesic use}

In the current study the $32.4 \%, 13.2 \%$, and $12.5 \%$ of the respondents took analgesics for the reason of headache, menstrual pain and fever pain management respectively. The $38.7 \%$ of the respondents chose the analgesics due to previous experience, the $19.9 \%$ by reading a publication and the $17.5 \%$ based on recommendations from others. With respect to a drug selection for the pain management, the $29.1 \%$ and $26.8 \%$ of the respondents in this study reported that Paracetamol and Ibuprofen as drugs that they prefer for a pain management (Table 5).

\begin{tabular}{|c|c|c|c|}
\hline Variable & Reason for the analgesic use & Frequency & $\%$ \\
\hline $\begin{array}{c}\text { For what reason(s) you } \\
\text { take analgesics? }\end{array}$ & $\begin{array}{c}\text { Headache } \\
\text { Menstrual symptoms (pains) } \\
\text { Fever } \\
\text { Dental pain } \\
\text { Back pain } \\
\text { Arthritis } \\
\text { Sore throat } \\
\text { Cold/Flu } \\
\text { Muscle pain }\end{array}$ & $\begin{array}{l}93 \\
38 \\
36 \\
32 \\
29 \\
19 \\
15 \\
13 \\
12\end{array}$ & $\begin{array}{r}32.4 \\
13.2 \\
12.5 \\
11.1 \\
10.1 \\
6.6 \\
5.2 \\
4.5 \\
4.1\end{array}$ \\
\hline $\begin{array}{l}\text { Reason for the choice of } \\
\text { analgesic?? }\end{array}$ & $\begin{array}{c}\text { Affordable } \\
\text { Previous experience } \\
\text { Advert on media } \\
\text { Publish materials I read } \\
\text { Recommended by friends/ family/ } \\
\text { health professionals } \\
\text { Others } \\
\text { Paracetamol } \\
\text { Ibuprofen } \\
\text { Diclofenac } \\
\text { Aspirin } \\
\text { Tramadol } \\
\text { Codeine }\end{array}$ & $\begin{array}{r}45 \\
113 \\
20 \\
58 \\
51 \\
\\
4 \\
91 \\
74 \\
84 \\
13 \\
49 \\
1\end{array}$ & $\begin{array}{r}15.4 \\
38.7 \\
6.8 \\
19.9 \\
17.5 \\
1.4 \\
29.1 \\
23.6 \\
26.8 \\
4.2 \\
15.7 \\
0.3\end{array}$ \\
\hline
\end{tabular}

Table 5: Reason for analgesic use, CHMS, Haramaya University, Harar, Eastern Ethiopia, Feb 2021.

\section{Discussion}

In this study 317 respondents were included from which $53.30 \%$ of them were males, while the remaining $46.70 \%$ were females. In the current study $90.9 \%$ of the respondents were single and the remains $9.1 \%$ were married. The $97.40 \%$ of the participants were under the age group of 21 to 27 years.

The $90.5 \%$ of the respondents had used analgesics. This result is relatively higher than a study conducted in Jeddah, Saudi Arabia, which showed that $84.4 \%$ of the participants used OTC analgesics [14]. In other study conducted in USA, the prevalence of analgesic self-medication was $49.7 \%$ which is lower than a prevalence of analgesic usage in this study [15]. The probable reason behind the lower percent usage of analgesic in the latter study might be due to the differences in sample size and educational status of the two countries.

In the current study the $63.8 \%$ of the respondents used analgesic in the last six months. The result is lower than the study conducted in Iranian University which showed that $76.6 \%$ of the respondents self-medicated with analgesics once or more than once in the 3 months of the study. This result is also lower than a study done in Saudi which revealed that $94.4 \%$ of participants used analgesics [16]. This irrational uses of medication leads to a development of toxicity and exposes to adverse effect if the medications when the drug is taken in an inaccurate dose or way.
In the present study the pattern of analgesic consumption is Ibuprofen (28.7\%), Diclofenac (25.7\%) and Paracetamol (21.7\%). The analgesic consumption pattern of this study is different from a study conducted in Iranian University in which the $59.6 \%$ of the respondents used acetaminophen followed by acetaminophen-codeine $(28.7 \%)$ and Ibuprofen $(4.8 \%)$ [16]. The analgesics consumption pattern of the current study is also different from a study done in Saudi Arabia that revealed that majority the respondents used Paracetamol as OTC analgesic (73.4\%) [17]. Similarly in other study conducted in Jeddah, Saudi Arabia, Acetaminophen (Paracetamol) was the most frequently used drug (86.1\%), followed by ibuprofen $(25.1 \%)$ and diclofenac (14.7\%) [14]. The probable reason for the differences in the findings might be due to difference in study population area.

In the current study the most common reasons analgesics were used for management headache $(31.8 \%)$, menstrual pain, (13.0\%) and fever $(12.3 \%)$. This is relatively similar to a study conducted in USA, in which the most common disease symptoms managed by analgesics were headache $(48.4 \%)$, followed by a cough, cold, and fever $(44.4 \%)$ and bone and joint pain (39.9\%) [15]. On the other hand this is slightly different from to a result of a study conducted in Jeddah, in which headache(71.1\%) was the major disease reason for usage of the analgesics followed by arthralgia (17.7\%) and toothache (17.4\%) [14]. This might shows that the difference for the reason of using analgesics could be raised because of 
differences in the morbidity patterns. The $38.7 \%$ of respondents replied that for reason of choosing the analgesics were previous experience of the use of the analgesic. This is in agreement with a study done in Saudi Arabia which revealed that previous experience with the drug (35.1\%) were the most common reason for choosing OTC analgesics use [14]. In this study the $29.1 \%$ of the respondents replied that Paracetamol was a drug that they would prefer for pain management. Similarly, a study conducted in Iranian University students in 2012, reported that Acetaminophen (59.6\%) was the most common self-medicated analgesic used by the respondents followed by acetaminophen-codeine $(28.7 \%)$ and Iboprofen (4.8\%) [16].

Significant proportion of the study participants had no adequate knowledge regarding side effects of analgesic drugs. With regard to this the $78.5 \%$ of the participants replied that large dose of Paracetamol may cause liver damage and the $81.3 \%$ the respondents were aware that large doses of Ibuprofen, Diclofenac, and Aspirin may cause gastric irritation/ulcer. This result is better than a study report of a study done in Jeddah, Saudi Arabia, in which $58.1 \%$ of the respondents had no knowledge about OTC analgesic side effects [17]. Also in a study conducted in Pakistan, only (25.0\%) correctly answered for a knowledge base question [18]. The present study result on the other hand, is in line with the result of a study from Lusaka Apex Medical University, showed that a $78.5 \%$ of students did not know the side effects of Ibuprofen [19].The probable reason for the differences in the findings might be due to different study population area.

In this study $78.3 \%$, the respondents stated that long time use of codeine can cause addiction This is analogous with a study conducted in Aston University which showed the average score of the 50 students for the knowledge based questions was 3.32 out of 7 (47.4\%). The result of the current study is slightly higher when compared to a study conducted in Nigeria where only $38.7 \%$ had good knowledge of opioid use [20]. Long term use of opioids including codeine may leads to addiction and potential adverse effects. Dependence on opioids has become a social problem [21, 22]

\section{Conclusion:}

This study showed the majority of the participants used analgesics for different reasons mainly for management of headache, menstrual pain and fever. Significant proportions of the study participants lack the appropriate knowledge about analgesics usage of analgesics. The study also showed that the majority of the participants used analgesics without a health professional consultation. Paracetamol is the most preferred drug for pain management in this study. The major reason for the choice of analgesics is primary the previous experience with the drug. All stakeholders including the college, CHMS, researchers, governments and all concerned bodies should give a better attention to close the knowledge gap about analgesics use seen in this study.

\section{Acknowledgement}

The author acknowledges Harmaya University College of health and medical Sciences for all positive co-operations for the undertaking of this study.

\section{Declarations}

Consent to publish: Not applicable

Funding: None

Competing interests: The author declare no competing interest.

Conflict of Interest: The authors declare no conflict of interest

Author's contribution
Author Lemlem Niguse involved in the conception and design of the study, participated in the literature searches, supervised data collection and analyzed data. Author Teshome Sosengo involved in the conception and design of the study, participated in the literature searches, analyzed data and wrote the manuscript. Both the authors approved the final manuscript.

Availability of data: All the data are available with the corresponding author, Lemlem Niguse.

\section{References}

1. Rajamäki T J., Puolakka PA. , Hietaharju A., Moilanen T and Jämsen E. (2020) Predictors of the use of analgesic drugs 1 year after joint replacement: a single-center analysis of 13,000 hip and knee replacements. Arthritis Research \& Therapy. 22(89): $1-11$.

2. IbrahimN K., and Alamoudi BM. (2018) Self-Medication with Analgesics: Knowledge and Attitudes of Senior Medical Students and Interns at King Abdulaziz University, Jeddah, Saudi Arabia. 21(1):1-9.

3. Joseph, T D., Robert, L T., Gary, CY and Gary R. (2014) Pharmacotherapy: A Pathophysiologic Approach. $9^{\text {th }}$ d. U.S: McGraw-Hill Education.

4. Kahsay H., Ahmedin M., Kebede B., Gebrezihar K., Araya H and Tesfay D. (2020) Assessment of Knowledge, Attitude, and Disposal Practice of Unused and Expired Pharmaceuticals in Community of Adigrat City, Northern Ethiopia. Journal of Environmental and Public Health.

5. Badzi C D and Ackumey MM. (2017) Factors influencing use of analgesics among construction workers in the GaEastmunicipality of the Greater Accra region, Ghana. Ghana Medical Journal. 51(4): 156-163.

6. Essa M A., Alshehri A., Alzahrani M., Bustami R., Adnan S and Alkeraidees A. (2019) Practices, awareness and attitudes toward self-medication of analgesics among health sciences students in Riyadh, Saudi Arabia. Saudi Pharmaceutical Journal. 27(2): 235-239.

7. Raja, M. A. G., Al-Shammari, S. S., Al-Otaibi, N., \& Amjad, M. W. (2020) Public Attitude and Perception about Analgesic and their Side Effects. Journal of Pharmaceutical Research International. 32(3): 35-52.

8. Shivamurthy S., Manchukonda R and Gurappanavar D. (2015) Evaluation of analgesic self-medication pattern among undergraduate medical students of Adichunchanagiri Institute of Medical Sciences, BG Nagar, Karnataka: a cross-sectional questionnaire-based study. International Journal of Basic \& Clinical Pharmacology. 4(3):438-441.

9. Alkilani A Z., Alkalbani R., Jaber D., Hamed R., Hamad I and Abumansour H. (2019) Knowledge, attitude, practice and satisfaction of patients using analgesic patches in Jordan. Tropical Journal of Pharmaceutical Research. 18 (8):17451753.

10. Abdu-Aguye S N., Shehu A and Ahmad UI. (2017) Management of musculoskeletal pain in retail drug outlets within a Nigerian community: a descriptive study. Pharmacy Pract (Granada). 15(1): 873.

11. Epstein D, Steinfeld Y, Marcusohn E, Ammouri H, Miller A. Health care professionals' knowledge of commonly used sedative, analgesic and neuromuscular drugs: A single center (Rambam Health Care Campus), prospective, observational survey. PLoS ONE. 2020.15(1).

12. Sarganas G., Buttery A K., Zhuang W., Wolf I K., Grams D and Rosario A S. (2015) Prevalence, trends, patterns and 
associations of analgesic use in Germany. BMC Pharmacology and Toxicology. 16(28): 1-13.

13. Mooataz, M.A., Hisham. A \& Alghanmi, R. (2016) Selfmedication among medical student in King Abdul-Aziz University. International Journal of Research in Medical Sciences. 4(3):942- 946.

14. Shaza, D.B \& Majid, M.A. (2018) Prevalence and Determinants of Over-the-Counter Analgesics Usage among Patients attending Primary Health Care Centers in Jeddah, Saudi Arabia. J Young Pharm. 10(1): 91-97.

15. Vandana, A \& Aslami, A. (2016) Analgesics self-medication among undergraduate students of a Rural Medical College. J Pharmacol Pharmacotherapy. 7(4): 182-183.

16. Sarahroodi, S., Maleki-Jamshid, A., Sawalha, A.F., Mikaili, P \& Safaeian, L. (2012) Pattern of self-medication with analgesics among Iranian University students in central Iran. J Fam Community Med. 19:125-129.

17. Nedaa, A., Ali, F A., Sukainah, A., Nuha, B A., Alhanouf, N A and Manar, S.A et al. Knowledge and attitude of analgesics use among Saudi population. International journal of medical science and public health. 2017; 7(2):137-143.

18. Fakhar, U. (2017) Poor knowledge of university students regarding paracetamol; a wakeup calls for public healthcare practitioners. Cogent Medicine. 4: 1-12.

19. Amina, R., Yassa, Y \& Amina, D. (2018) Assessing students' knowledge on the use of NSAIDs at Lusaka Apex Medical University. IOSR Journal of Pharmacy. 8(8): 36-45.

20. Akande-Sholabi1, W., Adisa, R., Ilesanmi, O., and Bello, A. (2019) Extent of misuse and dependence of codeine-containing products among medical and pharmacy students in a Nigerian University. BMC public health. 19:1709.

21. Wermeling, D. (2015) "Review of naloxone safety for opioid overdose: practical considerations for new technology and expanded public access. Therapeutic Advances in Drug Safety. 6(1):20-31.

22. Lozano, R., Naghavi, M and Foreman, K. (2012) Global and regional mortality from 235 causes of death for 20 age groups in 1990 and 2010: a systematic analysis for the global burden of disease study 2010. Lancet. 280(9859): 2095-2128. 